\title{
Experiencing Virtual Training via e-CPD: Analysis of Creative Thinking Skills
}

\author{
Rafiza Abdul Razak, Neela Kandan, and Farrah Dina Yusop
}

\begin{abstract}
This research investigated the experience of virtual training via electronic Continued Professional Development (e-CPD): analyzing teachers' creative thinking skills. The data analyzed was e-CPD content analysis related to teachers' creative thinking skills. There search finding portrays the gradation of creative thinking skills in experiencing e-CPD. The results contribute to improving virtual training for teachers' professional development thereby training teachers to become more efficient users of technology.
\end{abstract}

Index Terms-Virtual training, teachers' continued professional development, training design, creative thinking skills.

\section{INTRODUCTION}

Rapid changes in applying technology have forced educators to move fast and remain alert with respect to current trends in technology use in education. Nevertheless, are teachers able to acquire sufficient skills to suit the demand of technology in education? Teachers have been found deficient with respect to adequate technology skills to meet the demand of technology application in schools [1]. They thus must acquire appropriate knowledge and skills to improve their Information, Communication and Technology (ICT) skills to measure up to current trends in education. Therefore, the Preliminary Malaysian Education Blueprint [2] highlighted the importance of ICT in teaching and learning processes.

Ref. [3] concludes that there are seven factors contributing to the barriers in implementing technology in education. Inadequate training and low teachers' confidence levels in using ICT are among those seven barriers. This is further supported by [4] that state that teachers' levels of ICT usage are only moderate. Teachers with low confidence levels with respect to ICT use often refuse to use technology and, without proper support from schools and authorities, they tend to resist change [5]-[8].

Several studies also indicate that deficiencies in adequate training in ICT contribute to the barriers in ICT application among teachers [9]-[11]. Inappropriate training leads to a deficiency in ICT use among teachers so that adequate preparation prior to training must be carefully addressed [3], [12] to ensure the effectiveness of training and achieving its

Manuscript received December 12, 2013; revised June 10, 2014. This work was supported by the University of Malaya Research Grant No. RP002C-13ICT

Rafiza Abdul Razak, Neela Kandan, and Farrah Dina Yusop are with the Department of Curriculum and Instructional Technology, faculty of Education, University of Malaya, Kuala Lumpur, Malaysia (e-mail: rafiza@um.edu.my,neela_kprl@yahoo.com, farah@um.edu.my). objectives.

Teachers' continuing professional development has thus become a major topic in school reform and improvement research studies. Some studies have examined successful online environment for online professional development teaching [13], [14]. Accordingly, there search described here investigated the experience of virtual training through use of electronic Continued Professional Development (e-CPD) and analysis of teachers' creative thinking skills.

\section{REVIEW OF RELATED LITERATURE}

Ref. [15] explains that virtual training improves understanding, but a skillful and competent trainer or moderator is usually still required to effectively deliver and manage virtual training. Appropriate training delivery helps in achieving training objectives and [16] further advances the idea that virtual training is the best training platform. Moreover, use of such training allows facilitators to synchronously interact and involve themselves in activities with participants anytime and anywhere, very much like in an authentic learning environment.

\section{A. Teachers' Virtual Training}

Virtual training can provide a platform for supporting teachers as a community and can provide motivation, thereby increasing teachers' ICT and innovative skills [17]. Ref. [18] research findings indicate that, in addition to improving teachers' ICT skills, online training also increases their cognitive skills. Ref. [19] advocates that online training provides opportunities for teachers to interact and solve problems and this encourages them to collaborate in improving pedagogical skills.

Ref. [19] describes changes in teachers' behavior when conducting online training. Teachers with lesser ICT skills often show improvement and greater willingness to actively participate in improving their ICT skills. [20] further elaborates that virtual training can allow teachers to communicate through forums, thereby providing synchronous communication and interaction that encourages them to actively collaborate in improving each others'ICT skills.

\section{B. In Terms of Training Design, Virtual Training Design}

Ref. [21] introduces three components in designing virtual training. These components are learning management system web-based design applications. The underlying activities involve managing online video transmission and a virtual laboratory. This research emphasizes the components displayed in virtual training.

Ref. [22] on the other hand, emphasizes a human-behavior 
model in virtual training. They introduced via simulation a user-model method containing user information In order to make the simulation more realistic; various agent models were able to show human expressions were used.

In other circumstances, an Analysis, Design, Development, Implementation, and Evaluation (ADDIE) model has provided foundation and guidance in designing virtual training [1], [23]. Following the ADDIE model, the process guides users in preparing programs that meet targeted goals and effectively work as planned. The model also has been applied in training design involving social learning, active learning, distance learning, constructive learning, and cognitive learning. The ADDIE model is applicable to designing virtual training because of its systematic and easy-to-apply model criteria.

An older type of ADDIE model has been applied to linear design framework. Ref. [24] also utilizes the model in designing virtual training and highlights its use in a cyclic design framework. He explains the cyclic application of design in four different phases that include analysis of training, program design, program management, and evaluation.

\section{MethodOLOGY}

This research employed qualitative methodology in investigating the experience of teachers utilizing e-CPD, specific ally using a content-analysis technique. The e-CPD content was analyzed based on the creative thinking skills criteria [25]. The design and development process of e-CPD is first described, followed by analysis of e-CPD content according to three themes: elaborating, imagining, and synthesizing.

\section{A. Design of e-CPD}

E-CPD is an abbreviation for Electronic Continued Professional Development. It is a system specifically tailored for preparing professional development programs for teachers. The design of the system is based on virtual collaborative interaction between teachers and instructors. The development process is cyclic as it continuously evidences enhancement and maintenance procedures to ensure that the content of the virtual training appropriately suits the needs and demands of the teachers. This iterative process provides training suitable for the current demands of educational trends.

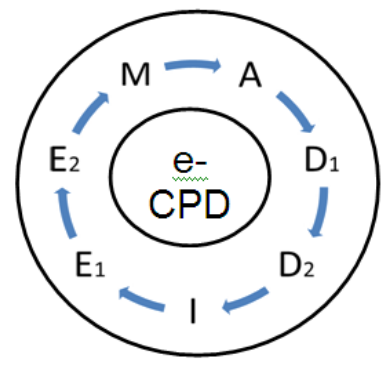

Fig. 1. E-CPDdesign framework.

The design of e-CPD provides useful links to accommodate teachers throughout the training process. These include reflection, forum, notes, news and announcement, activities, modules, multimedia academic materials, online video, and resources. The links assist teachers in accessing information and content of e-CPD.

Thus the Three-Phase Development (3PD) Model and ADDIE Model have been adapted [26] to designing the e-CPD framework. Fig. 1 illustrates the process of design and development of e-CPD. The model is designed to be conveniently suitable to meeting teachers' current needs and demands with respect to training information, communication, and technology skills. The framework describes a system for developing virtual training for teachers. The system is also applicable to other virtual professional training. It is intended to enhance and dynamically update educators' skills and knowledge.

The process of designing and developing e-CPD involves seven phases: Analysis (A), Design (D1), Development (D2), Implementation (I), Evaluation (E1), Enhancement (E2), and Maintenance (M). The analysis phase analyzes the demographic background of the teachers by investigating their ICT competency and needs. Furthermore, the conducive infrastructure for virtual training is also examined while preparing comfortable and appropriate conduct of the virtual training platform.

The design phase produces as toryboard explaining dynamic interaction and activities in e-CPD. This is essential because it provides an overview of each interface and thus explains aspects of interaction between teachers and trainers. The developmental phase represents the authoring and production processes of e-CPD, producing useful and dynamic multimedia integration in such forms as graphics, animations, and video elements to be integrated for advance accommodation throughout the virtual training process.

In implementinge-CPD, representing pre-virtual training, prior face-to-face training is still required to guide the teachers in maneuvering through the virtual training process. Registration and login procedures are also emphasized to assist teachers prior to their involvement in the virtual training. Close and step-by-step guidance are delivered throughout the implementation phase. This is crucially important since the success of the virtual training activity vitally depends on it. Following the pre-virtual training is the content interaction of teachers in e-CPD.

The evaluation phase explains the monitoring of teacher interaction and trainer activities. The momentum of responses, inquiries, and feedback are closely monitored with continuous trainer engagement. This ensures a positive relationship between trainers and teachers that is significant in making the virtual training a success.

The enhancement phase is designed specifically to ensure that quality of the virtual activity always meets teachers' demands and needs. All responses and feedbacks are carefully monitored. The cyclic motion of the e-CPD system design allows for continuous improvement and thus enhances the quality of e-CPD at all times [24]. To manage e-CPD, the maintenance phase essentially ensures that the process of virtual training in the system design of e-CPD is carefully maintained and organized.

\section{B. Results and Findings}

Based on analysis of the e-CPD content design, the levels 
of creative thinking skills teachers experienced during virtual training were investigated. The content design was categorized into six parts; news, forum, reflection, notes, instructional materials via online video, and activity.

\section{1) Elaborating}

The skill of elaborating can be identified by links such as news (Fig. 2) and activity (Fig. 3). Based on experience gained throughout the training, teachers were able to expand, modify, and add new knowledge. They suggested some ideas, as illustrated in Fig. 2, and shared them with the group in the activity and news sections.

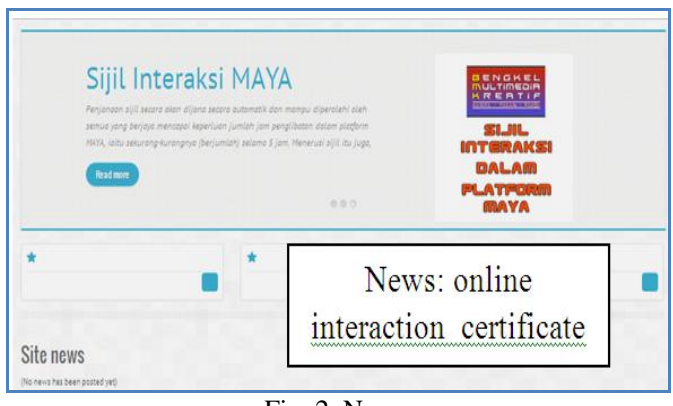

Fig. 2. News.

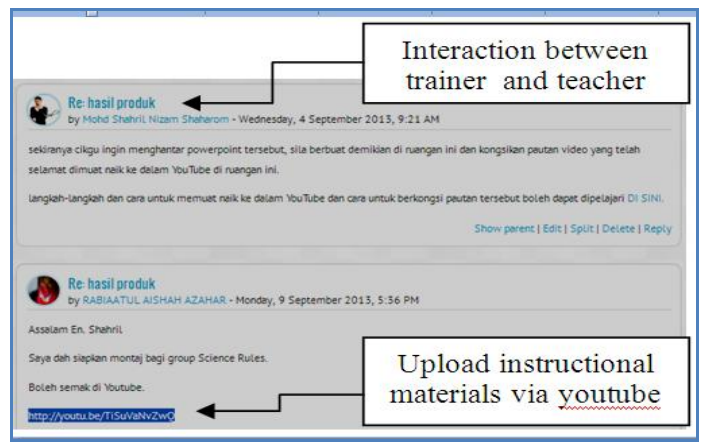

Fig. 3. Activity.

\section{2) Imagining}

In the forum (Fig. 4), the teachers efficiently generated new ideas. The notes such as online videos (Fig. 5), provided them with authentic visualization that gradually developed into new knowledge and skills.

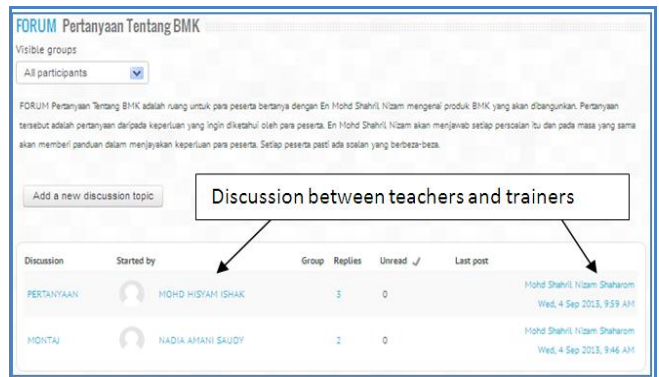

Fig. 4. Forum.

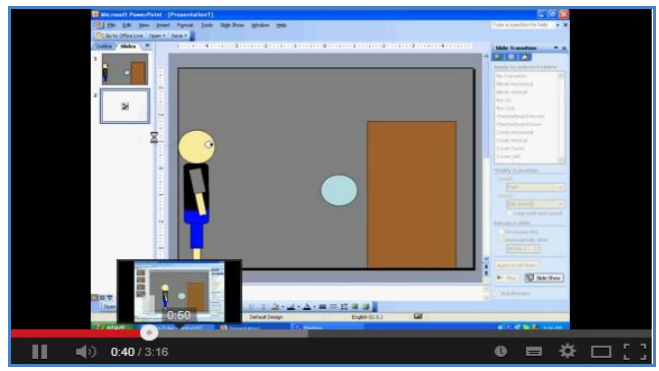

Fig. 5. Notes: Online video.

\section{3) Synthesis}

The synthesis skill involved the teachers in planning according to a procedure using step-by-step development of the product as requested and eventually produced instructional materials via online video (Fig. 6). The experience in virtual training also provided a platform for the teachers to relate and connect with the skills learned, synthesizing them as illustrated by reflections in the blog provided (Fig. 7).

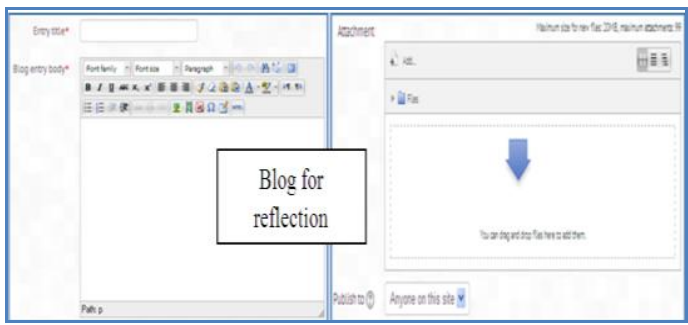

Fig. 6. Reflection: Blog.

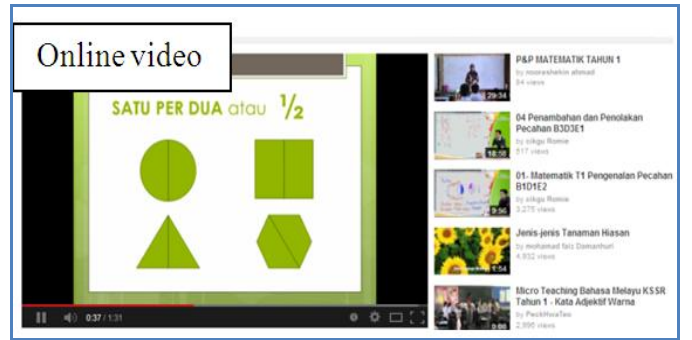

Fig. 7. Online video: Instructional materials produced by a group of teachers

\section{RESEARCH IMPLICATION}

The e-CPD experience improves teachers' understanding with respect to the production of instructional materials via online video [15]. The experience of participating in the forum and related activity in e-CPD further allows facilitators to synchronously interact and be involved in activities with participants anytime and anywhere just as in an authentic learning environment [16]. Furthermore, e-CPD provides opportunities for teachers to interact, solve problems, and collaborate while improving pedagogical skills [17].

The gradation of creative thinking skills in experiencing e-CPD illustrated in Fig. 8 shows that the e-CPD is a platform providing experience for teachers in improving cognitive skills and further enhancing innovative skills [17].

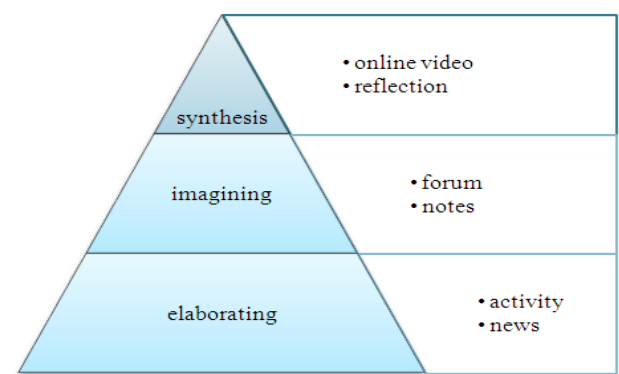

Fig. 8. The gradation of creative thinking skills in experiencing e-CPD

\section{CONCLUSION}

Based on the e-CPD virtual training experience, issues relating to inadequate training in ICT that contribute to the barriers in ICT application can be addressed [9]-[11]. More 
successful virtual training environments in terms of professional development of online teaching should been encouraged [13], [14]. Quality education requires quality teachers and quality teachers need quality training. E-CPD both provides the necessities and meets essential demands in improving educational quality.

\section{ACKNOWLEDGMENT}

The authors wish to thank the teachers involved in e-CPD. This work was supported in part by a grant from the University of Malaya Research GrantNo.RP002C-13ICT.

\section{REFERENCES}

[1] R. R. Mendoza. (2009). Designing training programs for professionals. [Online]. Available: http://www.scribd.com/doc/184895094/Designing-TrainingProgramsfor-Professionals-by-Hon-Rufo-R-Mendoza

[2] Ministry of Education, Preliminary Report: Malaysia Education Blueprint, Kuala Lumpur, Malaysia: Ministry of Education, 2012.

[3] J. Andrew. (2004). A review of the research literature on barriers to the uptake of ICT by teachers. British Educational Communications and Technology Agency (Becta). [Online]. Available: http://dera.ioe.ac.uk/1603/1/becta_2004_barrierstouptake_litrev.pdf

[4] K. S. Norazlina, "Barriers in computer and ICT utilization in teaching and learning among teachers in rural secondary schools in Kulai Jaya, Johor," Masters Thesis, Faculty of Education, University of Technology Malaysia, Malaysia, 2008.

[5] P. Bull, "Self-efficacy and technology integration: perceptions of first year teaching fellows to technology integration in education," presented at SITE Conf., 2009.

[6] G. Kurt, and D. Atay, "Prospective teachers' self-efficacy for technology integration: effects of an experiential method," in Proc. EDULEARN09, 2009, pp. 3117-3122.

[7] J. Bennett and L. Bennett, "A review of factors that influence the diffusion of innovation when structuring a faculty training program," The Internet and Higher Education, vol. 6, no. 1, pp. 53-63, 2003.

[8] G. R. Pajares. (2002). Self-efficacy beliefs in academic contexts: An $\begin{array}{lll}\text { outline. } & \text { [Online]. Available }\end{array}$ http://www.des.emory.edu/mfp/efftalk.html

[9] L. Webb, "Supporting technology integration: the school administrators' role," National Forum of Educational Administration \& Supervision Journal, vol. 28, no. 4, 2011.

[10] P. Aşkar et al., "Diffusion of computers in schools," in Encyclopedia of Distance Learning, C. Howard, Ed., USA: Idea-Group Reference, vol. 2, pp. 568-572, 2005.

[11] M. Groves and P. Zemel, "Instructional technology adoption in higher education: an action research case study," International Journal of Instructional Media, vol. 27, no. 1, pp. 57-65, 2000.

[12] Sarimah, "ICT application in teaching and learning mathematics and science: Educators perspectives," Master thesis, Universiti Perguruan Sultan Idris, Perak, Malaysia, 2003.

[13] B. Mandernach, E. Donnelli, A. Dailey, and M. Schulte, "A faculty evaluation model for online instructors: Mentoring and evaluation in the online classroom," Journal of Distance Learning Administration, vol. 8, no. 1, August 2013.

[14] A. Taylor and C. McQuiggan, "Faculty development programming: If we build it, will they come?" Educause Quarterly, vol. 12, no. 3, pp. 29-37, 2008
[15] M. Harbers, K. van den Bosch, and J. Meyer, "Self-explaining agents in virtual training," presented at EC-TEL 2008 PROLEARN Doctoral Consortium, 2009.

[16] T. Eggleston et al., Virtual Training: Moving Training Content and Delivery into The Virtual World, North America: New Leaf Partners, 2008.

[17] M. McAnuff-Gumbs, "Virtually there: making online training 'real' for Caribbean literacy coaches - what governments can do," MERLOT Journal of Online Learning and Teaching, vol. 7, 2011.

[18] E. Baran, A. P. Correia, and A. Thompson, "Transforming online teaching practice: critical analysis of the literature on the roles and competencies of online teachers," Distance Education, vol. 32, no. 3, pp. 421-439.

[19] S. Gold, "A constructivist approach to online training for online teachers," JALN, vol. 5, no. 1, 2001.

[20] S. A. Yucel, "E-learning approach in teacher training," Turkish Online Journal of Distance Education, vol. 7, no. 4, 2006.

[21] J. Wrubel, D. White, and J. Allen, High-Fidelity e-Learning: SEI's Virtual Training Environment (VTE), No. CMU/SEI-2009-TR-005, Carnegie-Mellon University Pittsburgh PA Software Engineering Institute, 2009

[22] Y. Murakami, Y. Sugimoto, and T. Ishida, "Modeling human behavior for virtual training systems," in Proc. the National Conference on Artificial Intelligence, vol. 20, no. 1, Menlo Park, CA, Cambridge, MA, London, AAAI Press, MIT Press, 1999, 2005.

[23] S. Hu, "Design an effective model for training the trainers," Master thesis, University of Ljubljana, 2004.

[24] L. Kirkpatrick, Transferring Learning to Behavior: Using the Four Levels to Improve Performance, San Francisco: Berrett-Koehler Publishers, 2005

[25] D. H. Jonassen, Computers as Mindtools for Schools: Engaging Critical Thinking, Columbus, OH: Prentice-Hall, 2000.

[26] R. E. Mayer, The Cambridge Handbook of Multimedia Learning, USA Cambridge University Press, 2005.

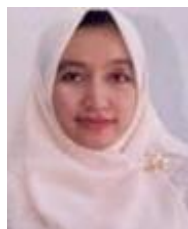

Rafiza Abdul Razak is a senior lecturer in University of Malaya, Kuala Lumpur, Malaysia. She holds a PhD with specialization in instructional design and technology and has ten years of experience as a lecturer at the University of Malaya and five years of experience in a secondary school

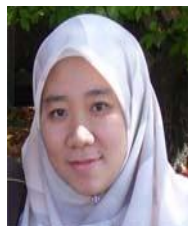

Farrah Dina Yusop is a senior lecturer at the University of Malaya, Kuala Lumpur, Malaysia. In 2010 she received a PhD from Iowa State University (ISU), USA, in the fields of curriculum and instructional technology (CIT) and human computer interaction (HCI). She has published more than 50 journal and conference papers. and actively conducts research and publishes in the areas of civic-minded instructional designer (CMID) conceptual framework, teaching and learning in higher education contexts, Web 2.0, social media, educational games, and mobile learning.

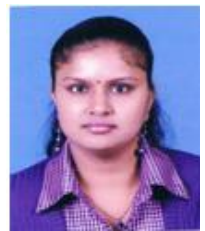

Neela Kandan specializes in instructional design and technology. She has been working as a teacher at a Malaysian Tamil primary school for the past four years. She is in the process of completing her Master's in Instructional Technology. 